\title{
Editorial
}

\section{Baveno VI Recommendation on Avoidance of Screening Endoscopy in Cirrhotic Patients: Not Quite There Yet!}

\author{
Susana Rodrigues \\ Department of Gastroenterology, Centro Hospitalar de São João, Porto, Portugal
}

\section{Keywords}

Cirrhosis · Noninvasive diagnosis · Fibrosis · Portal hypertension

\section{Evitar o Rastreio Endoscópico em Doentes com Cirrose Segundo a Recomendação do Baveno VI: Ainda Nós Estamos Lá!}

\section{Palavras Chave}

Cirrose · Diagnóstico não-invasivo · Fibrose · Hipertensão portal

Although over the last decade, many studies have shown that noninvasive methods, such as ultrasound, transient elastography, and simple blood tests, can accurately predict the presence of clinically significant portal hypertension (CSPH), most were performed in viral hepatitis-related cirrhosis patients [1-7]. Until very recently, the European Association for the Study of the Liver (EASL) guidelines stated that there was not enough evidence to replace endoscopy with noninvasive methods [8].

\section{KARGER}

E-Mail karger@karger.com www.karger.com/pjg
(C) 2017 Sociedade Portuguesa de Gastrenterologia Published by S. Karger AG, Basel

Karger

Open access

This article is licensed under the Creative Commons AttributionNonCommercial-NoDerivatives 4.0 International License (CC BYNC-ND) (http://www.karger.com/Services/OpenAccessLicense). Usage and distribution for commercial purposes as well as any distribution of modified material requires written permission.
In 2015, the Baveno VI consensus report introduced some new concepts in the world of hepatology, namely the definition of compensated advanced chronic liver disease (cACLD) and the use of noninvasive methods to avoid screening of varices in these patients in the absence of ongoing liver injury. cACLD reflects the spectrum of severe fibrosis or cirrhosis as a continuum in asymptomatic patients, indistinguishable on clinical grounds. $\mathrm{Pa}$ tients with cACLD, liver stiffness $<20 \mathrm{kPa}$, and platelet count $>150,000$ were considered at low risk for having varices requiring primary prophylaxis, consequently avoiding endoscopy screening, irrespective of etiology. Furthermore, the report states that regarding patients with virus-related CACLD, noninvasive methods can sufficiently rule in CSPH alone or combined with platelet count and spleen size [9].

The Baveno VI report regarding endoscopy surveillance in CACLD patients was not based upon robust data and remains a matter of controversy and debate. Nevertheless, following its publication, many centers published their retrospective data validating the report [10-13]. Data from a cohort of 310 patients from 2 centers in London showed that the Baveno VI report spared endoscopy surveillance in $33 \%$ of patients. This is the largest cohort of patients with different etiologies (55\% viral) validating

Dr. Susana Rodrigues

Department of Gastroenterology, Centro Hospitalar de São João

Alameda Prof. Hernâni Monteiro

PT-4200-319 Porto (Portugal)

E-Mail susanagrodrigues@gmail.com 
the criteria [14]. Augustin et al. [15] compiled publications and abstracts regarding the validation of the Baveno VI report (a total of 3 publications and 6 abstracts) with a total of 2,500 patients, applying the criteria to 1,000 . The guidelines could have spared $20 \%$ of endoscopies, but still missed patients who needed primary prophylaxis and, in almost $40 \%$ of the patients, an endoscopy could have been avoided altogether [15].

The Baveno consensus report was a first step in the direction of applying noninvasive methods to select patients for endoscopy screening. Further research developing new cutoffs or applying other noninvasive methods is needed. In this issue, in "Baveno VI Recommendation on Avoidance of Endoscopy in Cirrhotic Patients: Are We There Yet?" Silva et al. [16] set out to determine the Baveno VI criteria in a retrospective cohort of 97 patients with hepatitis C-associated cirrhosis. In this cohort, endoscopy was avoided in $11.3 \%$ of patients, and it further suggested that by skewing the cutoffs to $<120,000$ platelets and liver stiffness to $>30 \mathrm{kPa}$, endoscopy could be avoided in $27.8 \%$ of patients, supporting the validation of the Baveno VI recommendations [16].

There is still a clear lack of prospective data validating the Baveno VI recommendations in patients with cACLD with different etiologies (nonviral causes, such as alcoholic and nonalcoholic liver disease, are underrepresented in most studies) and establishing that endoscopy avoidance is clearly safe and cost-effective. Although a large proportion of patients can avoid endoscopic screening, it is important to underline that some patients are misclassified and will not be offered primary prophylaxis.
A step in the right direction was taken in the recently published ANTICIPATE study, a multinational study including 518 cACLD patients that blended retrospective and prospective data. The aim of this study was to develop continuous risk prediction models based on noninvasive methods to predict the risk of CSPH, varices, and varices needing treatment in a large multinational cohort of compensated cirrhotic patients who had paired noninvasive tests (transient elastography, spleen diameter, and platelet count) and endoscopy or hepatic venous pressure gradient measurement. The study successfully developed nomograms that could predict the development of CSPH and varices requiring treatment in patients with compensated cirrhosis. The same simple noninvasive tools could not reliably identify the population of patients having a low risk of all-size varices, partly explained by the fact that endoscopy is not a perfect gold standard for the diagnosis of gastroesophageal varices [17]. Although this study developed an accurate predictive model based on a large number of patients from various centers, prospective studies including more cirrhotic patients with nonviral etiologies are needed to further validate the findings.

The response to the question "Baveno VI recommendation on avoidance of screening endoscopy in cirrhotic patients - are we there yet?" is: not quite and look before you leap!

\section{Disclosure Statement}

The authors have no conflicts of interest to declare.

\section{References}

1 Thomopoulos KC, Labropoulou-Karatza C, Mimidis KP, Katsakoulis EC, Iconomou G, Nikolopoulou VN: Non-invasive predictors of the presence of large oesophageal varices in patients with cirrhosis. Dig Liver Dis 2003;35: 473-478.

2 Bureau C, Metivier S, Peron JM, Selves J, Robic MA, Gourraud PA, et al: Transient elastography accurately predicts presence of significant portal hypertension in patients with chronic liver disease. Aliment Pharmacol Ther 2008;27:1261-1268

3 Vizzutti F, Arena U, Romanelli RG, Rega L, Foschi M, Colagrande S, et al: Liver stiffness measurement predicts severe portal hypertension in patients with HCV-related cirrhosis. Hepatology 2007;45:1290-1297.

Baveno VI Recommendation: Not Quite There Yet!
4 Cástera L, Le Bail B, Roudot-Thoraval F, Bernard PH, Foucher J, Merrouche W, et al: Early detection in routine clinical practice of cirrhosis and oesophageal varices in chronic hepatitis C: comparison of transient elastography (FibroScan) with standard laboratory tests and non-invasive scores. J Hepatol 2009; 50:59-68.

5 Shi KQ, Fan YC, Pan ZZ, Lin XF, Liu WY, Chen YP, et al: Transient elastography: a meta-analysis of diagnostic accuracy in evaluation of portal hypertension in chronic liver disease. Liver Int 2013;33:62-71.

6 Berzigotti A, Seijo S, Arena U, Abraldes JG, Vizzutti F, García-Pagán JC, Pinzani M, Bosch J: Elastography, spleen size, and platelet count identify portal hypertension in patients with compensated cirrhosis. Gastroenterology 2013;144:102-111.
7 Augustin S, Millan L, Gonzalez A, Martell M, Gelabert A, Segarra A, Serres X, et al: Detection of early portal hypertension with routine data and liver stiffness in patients with asymptomatic liver disease: a prospective study. J Hepatol 2014;60:561-569.

8 European Association for the Study of the Liver; Asociacion Latinoamericana para el Estudio del Higado: EASL-ALEH Clinical Practice Guidelines: non-invasive tests for evaluation of liver disease severity and prognosis. J Hepatol 2015;63:237-264.

9 de Franchis R; Baveno VI Faculty: Expanding consensus in portal hypertension: report of the Baveno VI Consensus Workshop: stratifying risk and individualizing care for portal hypertension. J Hepatol 2015;63:743-752.

There Yet! 
10 Perazzo H, Fernandes FF, Castro Filho EC, Perez RM: Points to be considered when using transient elastography for diagnosis of portal hypertension according to the Baveno's VI consensus. J Hepatol 2015;63:10481049.

11 Thabut D, Bureau C, Layese R, Bourcier V, Corvy L, Petrov-Sanchez V, et al: New recommendations of Baveno VI conference for the screening of portal hypertension: an independent sequential validation in patients with compensated viral cirrhosis taking into account virological status (ANRS CO12 CIRVIR cohort). J Hepatol 2016;64(suppl 2):S178.
12 Paternostro R, Schwarzer R, Ferlitsch M, Schwalb P, Reiberger T, Mandorfer M, et al: Exclusion of varices via transient elastography combined with platelet count according to the Baveno VI guidelines can only be made for large not small varices. J Hepatol 2016; 64(suppl 2):S283.

13 Chang PEJ, Cheah CCM, Li WJ, Wong YE: Real-world validation of Baveno VI recommendations for screening endoscopy in patients with compensated advanced chronic liver disease. J Hepatol 2016;64(suppl 2):S178.

14 Maurice JB, Brodkin E, Arnold F, Paine H, Navaratnam AMD, Khawar S, et al: The Baveno VI guidelines: can we confidently identify low risk cirrhotic patients not requiring endoscopic surveillance for varices? J Hepatol 2016;65:899-905.
15 Augustin S, Pons M, Genesca J: Validating the Baveno VI recommendations for screening varices. J Hepatol 2016;pii:S0168-8278.

16 Silva MJ, Bernardes C, Pinto J, Loureiro R, Duarte P, Mendes M, Calinas F: Baveno IV recommendation on avoidance of endoscopy in cirrhotic patients - are we there yet? GE Portuguese J Gastroenterol 2016, DOI: $10.1159 / 000452693$.

17 Abraldes JG, Bureau C, Stefanescu H, Augustin S, Ney M, Blasco H, Procopet B, Bosch J, Genesca J, Berzigotti A; Anticipate Investigators: Noninvasive tools and risk of clinically significant portal hypertension and varices in compensated cirrhosis: The "Anticipate" study. Hepatology 2016;64:2173-2184. 